\title{
Ved en trono a la noble igualdad. Soñar con Rousseau en América Latina
}

\author{
Waldo Ansaldi \\ CONICET - UBA \\ A Mariana, una vez más. \\ El hombre ha nacido libre, y en \\ todas partes se halla entre cadenas. \\ Jean-Jacques Rousseau, El contrato social.
}

\begin{abstract}
Resumen
El artículo persigue el objetivo de mostrar, resumidamente, la impronta de Jean-Jacques Rousseau en los procesos independentistas latinoamericanos, particularmente su propuesta de una libertad igualitaria, que fue retomada por algunos de los más destacados dirigentes revolucionarios, sobre todo en el área rioplatense, donde Mariano Moreno, Bernardo de Monteagudo y José Artigas aparecieron como los más preclaros y decididos impulsores del pensamiento del ginebrino, el cual, por otra parte, llegó relativamente temprano al continente, donde fue perseguido por el Santo Oficio por postular la soberanía popular y la democracia.

El artículo analiza también la relación entre ciudadanía, ciudadano y derecho, a la que no fue ajena la cuestión de género, como también la relación entre ciudadanía y libertad, considerada, por Moreno, como principio fundante de una nueva era, coherente con el proyecto emancipador generado por las proposiciones roussonianas.

Finalmente, el artículo, si bien rescata la importancia de las ideas del ginebrino en las luchas por la independencia y por la constitución de un nuevo orden social y político, no deja de advertir el breve tiempo que tuvo la impronta de las mismas, derrotadas por propuestas de orden más moderadas, cuando no conservadoras.
\end{abstract}

Palabras claves: Jean-Jacques Rousseau - Independencias latinoamericanas - Libertad igualitaria Ciudadanía - Género

\begin{abstract}
ANSALDI, Waldo“Ved en trono a la noble Igualdad. Soñar con Rousseau en América

Latina”, en Avances del Cesor, Año IX, N 9, 2012, pp. 87-107.
\end{abstract}

This article offers a brief outlining of the marks made by Jean-Jacques Rousseau's ideas on Latin American independence processes, particularly the idea of an egalitarian freedom, which was assumed by some of the most outstanding revolutionary leaders. It was mainly so in the Rio de la Plata area, where Mariano Moreno, Bernardo de Monteagudo and José Artigas were the most illustrious and determined 
driving forces of Rousseau's thinking, which, moreover, arrived relatively early in the continent, where it was persecuted by the Inquisition because of its ideas of popular sovereignty and democracy.

The article also analyzes the relationship between citizenship, citizen and rights, of which gender was not excluded. Also it studies the relationship between citizenship and freedom, which was considered by Moreno as a founding principle of a new era, coherent with the emancipating project generated by rousseaunian propositions.

Finally, even when the article underlines the importance of Rousseau's ideas in the struggle for independence and for the constitution of a new political and social order, it also underlines the short time these ideas survived. They were defeated by ideas of a more moderated order, or even more a conservative one.

Key words: Jean-Jacques Rousseau - Latin American independence processes - Egalitarian freedom - Citizenship - Gender

\section{Actualidad de Rousseau}

Que el pensamiento de Jean-Jacques Rousseau siga teniendo vigencia, trescientos años después de su nacimiento, nos dice mucho de la frustración del mejor proyecto de la Modernidad, el de la razón liberadora, del cual el ginebrino fue estandarte, desplazado por el de la razón instrumental, expresado por el utilitarismo inglés. La oclusión, la derrota, del primer proyecto no implica necesariamente abandonarlo, todo lo contrario. Tampoco, es obvio, recuperarlo sin cambios. Como en tantas cosas, mutatis mutandi. Por caso, sería un contrasentido mantener la posición de Rousseau respecto de las mujeres. La cuestión es recuperar de Rousseau sus propuestas históricamente no agotadas.

En el espacio acotado para este artículo, quiero señalar tan solo unos puntos que considero bien relevantes para dar cuenta de la actualidad de Rousseau: soberanía popular, democracia, republicanismo (que conllevaba una valoración positiva de la libertad, afirmando la capacidad del Estado para realizarla, en contraste con John Locke y su defensa del Estado mínimo) y, sobre todo, su concepción de la libertad igualitaria, es decir, la libertad que torna a todos iguales sin dejar de ser libertad. Se trata de la base necesaria para una sociedad igualitaria, promotora de la personalidad de cada uno de sus miembros sin ser niveladora y capaz de potenciar las libertades civiles y políticas para evitar su derivación (degeneración) en privilegios. De lo que trata la herencia del ginebrino, entonces, no es sólo la democracia real, sino también la emancipación de la humanidad. La utopía socialista (uso la expresión en sentido positivo), la de la sociedad de hombres libres e iguales, en la cual la libertad desplazaría a la necesidad, tiene esa raíz roussoniana. ${ }^{1}$

1 Retomo aquí, muy condensadamente, una excelente argumentación realizada hace varias décadas, sin haber perdido vigencia sustantiva, por DELLA VOLPE, Galvano, Rousseau y Marx, Editorial Platina, Buenos Aires, 1963. 


\section{Una demanda radical: igualdad}

Exceptuando a los diggers (o true levellers) de la Inglaterra del interregno republicano, a mediados del siglo XVII, la más fuerte reivindicación de la igualdad fue explícitamente formulada por Jean-Jacques Rousseau en el siglo siguiente. Bajo la forma de igualdad ante la ley fue consagrada como valor universal por la Déclaration des droits de l'Homme et du Citoyen proclamada por los revolucionarios franceses en $1789 .{ }^{2}$ De allí en más, la igualdad -aun con todos los límites existentes entre la igualdad ante la ley, es decir, formal, y la igualdad real-fue pensada como un medio de reducir las diferencias entre los hombres (más tarde, lucha mediante, también entre las mujeres), entroncándose con las luchas por la democracia política y social, sea desde una perspectiva reformista o desde una revolucionaria.

En América Latina, este vocablo novedoso tuvo un tiempo -el de la fase radical de los procesos independentistas, entre 1793-1804, en el caso haitiano, y 1810-1815, en el de las colonias españolas- en el que fue generosamente invocado, abandonándoselo o reduciendo su apelación a medida que era percibido como peligroso por las clases propietarias. Bernardo Monteagudo, por ejemplo, sostuvo:

Todos los hombres son iguales en presencia de la ley: el cetro y el arado, la púrpura y el humilde ropaje del mendigo, no añaden ni quitan una línea a la tabla sagrada de los derechos del hombre. ... Los aduladores de los déspotas declaman como unos energúmenos contra este sistema, y se esfuerzan en probar con tímidos sofismas que la igualdad destruye el equilibrio de los pueblos, derriba la autoridad, seduce la obediencia, invierte el rango de los ciudadanos y prepara la desolación de la justicia. Confundiendo por ignorancia los principios, equivocan por malicia las consecuencias y atribuyen a un derecho tan sagrado los males que arrastran su abuso y usurpación.

2 El artículo $6^{\circ}$ dice: "Todos los ciudadanos, siendo iguales a sus ojos [los de la ley], son igualmente admisibles a todas las dignidades, cargos y empleos públicos, según su capacidad, sin ningún otra distinción que la de su virtud o su talento". Previamente, el artículo $1^{\circ}$ proclama enfáticamente: "Los hombres nacen libres e iguales en derechos y las distinciones sociales no pueden fundarse más que en la utilidad común". Antes de 1789, la "Declaración de derechos hecha por los representantes del buen pueblo de Virginia" - una de las colonias insurrectas-, en 1776, ya había señalado, en la Sección 1, la condición natural de los hombres como "igualmente libres e independientes". Como se ha señalado muchas veces, la expresión hombre no fue formulada en términos genéricos, sino específicamente referida a los varones. Fue por reacción a esa reducción y por defender el derecho de las mujeres a la igualdad que Marie Gouze, más conocida como Olympe de Gouges, presentó en 1791 una Déclaration des Droits de la Femme et de la Citoyenne, texto pionero en la larga lucha de las mujeres por la efectiva universalización de los derechos humanos. La propuesta era muy avanzada para una época decididamente dominada por la misoginia, incluso para los revolucionarios más radicales, que la rechazaron. La luchadora, que se opuso a la decapitación de Louis XVI y adhirió a los girondinos, fue detenida, enjuiciada y guillotinada en 1793. 
No es la igualdad la que ha devastado las regiones, aniquilado los pueblos y puesto en la mano de los hombres el puñal sangriento que ha devorado su raza. ${ }^{3}$

Formalmente, el derecho a la igualdad -a veces expresado genéricamente, otros acotado como igualdad ante la ley- tuvo rango constitucional, $v . g r$., en Venezuela (1811, artículos 152 y 154), en México (1814, artículo 24), en el proyecto del Ayuntamiento de Guatemala (1810, artículos $4^{\circ}$ y $\left.5^{\circ}\right)$, y estuvo presente en proyectos no sancionados, como los artiguistas de 1813 para la Provincia Oriental del Uruguay y federal para las Provincias Unidas del Río de la Plata.

$\mathrm{Al}$ igual que sus pares revolucionarios franceses, los hombres hispanoamericanos no reconocieron a las mujeres todos los derechos fundamentales, lo cual no obstaba para que algunos las instaran a desempeñar un fundamental papel en la educación... de los varones. El jacobino tucumano Bernardo Monteagudo es un buen ejemplo de esa posición, tal como se aprecia en el artículo "A las americanas del sud", publicado en la edición del 20 de diciembre de 1811 de la Gaceta de Buenos Aires:

La consecuencia que voy a deducir es fácil prevenirla: uno de los medios de introducir las costumbres, fomentar la ilustración en todos sus ramos, y sobre todo, estimular y propagar el patriotismo es que las señoras americanas hagan la firme y virtuosa resolución de no apreciar ni distinguir más que al joven moral, ilustrado, útil por sus conocimientos, y sobre todo patriota, amante sincero de la LIBERTAD, y enemigo irreconciliable de los tiranos. Si las madres y esposas hicieran estudio de inspirar a sus hijos, maridos y domésticos estos nobles sentimientos, y si aquéllas, en fin, que por sus atractivos tienen derecho a los homenajes de la juventud, emplearan el imperio de su belleza y artificio natural en conquistar desnaturalizados y electrizar a los que no lo son, ¿qué progresos no haría nuestro sistema? ${ }^{4}$

El hombre revolucionario se permite indicarle a la mujer a quién seducir, si es necesario, apelando a "sus atractivos", todo "por la patria que desea ser libre" (como escribe líneas después). Es decir, una concepción instrumental.

Obviamente, la demanda de igualdad caló mucho más hondo allí donde su ausencia estaba ligada inescindiblemente con la falta de libertad (y probablemente por su mayor relación con la metrópolis francesa), en la brutal sociedad esclavista de Saint-Domingue, impactó en Venezuela (Coro y Cariaco, en 1795 y 1798) y no fue significativa en Brasil. A la postre, muchos leyeron la igualdad en términos de terror: así, el haitiano, a menudo asociado con el jacobino y/o con el racismo inverso (contra los blancos, a los cuales, además se prohibió durante más de un siglo el ejercicio del derecho de sufragio), generó, entre buena parte de

3 “Continúan las observaciones didácticas", Gaceta de Buenos Aires, 21 de febrero de 1812, en MONTEAGUDO, Bernardo, Obras políticas, Librería La Facultad, Buenos Aires, 1916, pp. 131-132.

4 Ídem, pp. 98-99; mayúsculas en el original. 
los grupos propietarios, el "miedo a la revolución" y posiciones, a veces furibundas, contra la demanda de igualdad, tal como se aprecia en el fraile mexicano Servando Teresa de Mier:

De la igualdad, que absolutamente no puede haber entre los hombres, sino para ser protegidos por justas leyes sin excepción, los débiles y necios contra los fuertes y entendidos, dedujeron los franceses que se debían degollar para igualarse en los sepulcros, donde únicamente todos somos iguales. ${ }^{5}$

La igualdad fue, a menudo, aceptada en términos políticos e incluso -bajo el fetichismo "ante la ley"- jurídicos, pero en la práctica fue negada, sea apelando a los designios de la Providencia, en el caso de los religiosos, sea invocando a la naturaleza, en el de los positivistas. La igualdad fue el valor de la Modernidad más duramente reprimido, no sólo en América Latina.

En las estrofas de varios Himnos nacionales latinoamericanos (que no son siempre las mismas que se cantan en la actualidad) se invoca explícitamente a la libertad, pero sólo los de Argentina y Paraguay (y más tarde el Brasil republicano) invocan también a la igualdad.

Argentina (Marcha Patriótica, 1812-1813)

¡Oíd, mortales!, el grito sagrado:

¡libertad!, ;libertad!, ;libertad!

Oíd el ruido de rotas cadenas

ved en trono a la noble igualdad.

...

Mas los bravos que unidos juraron

su feliz libertad sostener,

a estos tigres sedientos de sangre

fuertes pechos sabrán oponer

...

La victoria al guerrero argentino

con sus alas brillantes cubrió,

y azorado a su vista el tirano

con infamia a la fuga se dio;

sus banderas, sus armas se rinden

por trofeos a la Libertad.

Bolivia: (1845)

Loor eterno a los bravos guerreros

Cuyo heroico valor y firmeza

5 MIER, Fray Servando Teresa de, Historia de la Revolución de la Nueva España, 1813, apud ROMERO, José Luis, ROMERO, Luis Alberto (compiladores) Pensamiento político de la Emancipación, Biblioteca Ayacucho, Caracas, 1977, T. II, p. 50. 
Conquistaron las glorias que empiezan

Hoy Bolivia feliz a gozar

Que sus nombres el mármol y el bronce

A remotas edades transmitan

$\mathrm{Y}$ en sonoros cantares repitan:

Libertad! Libertad! Libertad!

Aquí alzó la justicia su trono

que la vil opresión desconoce,

y en su timbre glorioso legose

libertad, libertad, libertad.

\section{Brasil:}

Imperio

Hino da Independencia (música compuesta por el propio emperador, Pedro I)

Já podeis, da Pátria filhos,

Ver contente a mãe gentil;

Já raiou a liberdade

No horizonte do Brasil.

Brava gente brasileira!

Longe vá... temor servil:

Ou ficar a pátria livre

Ou morrer pelo Brasil.

República (1890)

Ouviram do Ipiranga às margens plácidas

De um povo heróico o brado retumbante,

E o sol da liberdade, em raios fúlgidos,

Brilhou no céu da Pátria nesse instante.

Se o penhor dessa igualdade

conseguimos conquistar com braço forte, em teu seio, ó liberdade,

desafia o nosso peito a própria morte!

\section{Chile:}

El que ayer doblegábase esclavo, hoy ya libre y triunfante se ve;

Libertad es la herencia del bravo;

la victoria se humilla a su pié.

\section{Colombia (1887, letra del Presidente Rafael Núñez)}

Cesó la horrible noche! La libertad sublime derrama las auroras de su invencible luz. 
La humanidad entera, que entre cadenas gime, comprende las palabras del que murió en la cruz

",

Mas no es completa gloria vencer en la batalla, que al brazo que combate lo anima la verdad.

La independencia sola al gran clamor no acalla; si el sol alumbra a todos, justicia es libertad.

\section{Ecuador:}

Tras la lid la victoria volaba, libertad tras el triunfo venía, y al león destrozado se oía de impotencia y despecho rugir

\section{El Salvador:(1879)}

Le protege una férrea barrera Contra el choque de ruin deslealtad, Desde el día que en su alta bandera Con su sangre escribió: ¡Libertad!

Libertad es su dogma, es su guía Que mil veces logró defender; Y otras tantas, de audaz tiranía Rechazar el odioso poder.

\section{México:}

Guerra, guerra! en el monte, en el valle, Los cañones horrísonos truenen Y los ecos sonoros resuenen Con las voces de ¡Unión! ¡Libertad!

\section{Paraguay: (1846)}

Paraguayos, ¡República o Muerte! Nuestro brío nos dio libertad; Ni opresores, ni siervos, alientan, Donde reinan unión, e igualdad, ...

Libertad y Justicia defiende Nuestra Patria; Tiranos, ¡oíd!

\section{Perú:}

Mas apenas el grito sagrado ¡Libertad! En sus costas se oyó, 
la indolencia de esclavo sacude,

la humillada cerviz levantó.

...

Por doquier San Martín inflamado, Libertad, libertad, pronunció, y meciendo su base los Andes

la anunciaron, también a una voz.

\section{Provincias Unidas del Centro de América ${ }^{6}$}

Ya se ve, Patria mía, en tu oriente nuevo sol esparcir claridad; ya podemos con voz reverente pronunciar: Dios, Unión, Libertad.

\section{República Dominicana:}

Libertad! Que los ecos se agiten, Mientras llenos de noble ansiedad Nuestros campos de gloria repiten Libertad! Libertad! Libertad!

\section{Uruguay:}

Orientales, la Patria o la tumba.

Libertad, o con gloria morir.

...

¡Libertad, libertad, Orientales!

Este grito a la patria salvó.

Y a sus bravos, en fieras batallas,

De entusiasmo sublime inflamó.

...

¿Libertad! en la lid clamaremos

Y muriendo, también ;Libertad!

...

Orientales, la Patria o la tumba.

Libertad, o con gloria morir!

Venezuela:

¡Abajo Cadenas! ¡Abajo Cadenas!

gritaba el señor, gritaba el señor,

6 El himno de la unión centroamericana, conocido como La Granadera, rigió durante la breve existencia de la misma. En 1971 fue formalmente adoptado como tal por la Organización de Estados Centroamericanos. 
y el pobre en su choza Libertad pidió.

A este santo nombre tembló de pavor

el vil egoísmo, que otra vez triunfó.

Los de Cuba, Haití, Honduras, Panamá y Puerto Rico no incluyen ninguno de los dos términos. El de Guatemala tampoco, al menos de modo explícito, aunque implícitamente se alude a libertad al negar la esclavitud:

Guatemala feliz! que tus aras

no profane jamás el verdugo;

ni haya esclavos que laman el yugo

ni tiranos que escupan tu faz.

En cuanto al de Costa Rica, el vigente no contiene referencias a la libertad ni a la igualdad, pero la letra del primer himno, escrita en 1873, sí a la primera, al parecer aludiendo al final de la intervención del aventurero norteamericano William Walker en América Central, a cuya derrota Costa Rica contribuyó decisivamente,

Costa Rica rompió las cadenas

que la ataban a extraño poder

soltó al viento su propia bandera

y el imperio fundó de la ley.

Libertad proclamó entusiasmada,

Libertad en el orden y el bien;

del progreso ciñó la guirnalda

en su virgen y cándida sien!

Lo que las letras de los himnos muestran, en la elocuencia de su significado simbólico, es el desplazamiento de la simultánea demanda radical de igualdad y libertad hacia la proclamación (retórica, no real) de la segunda. El liberalismo se hizo fuerte invocando la libertad en detrimento de la igualdad. El socialismo partió de una reivindicación de ambas, pero la práctica de los mal llamados "socialismos reales" implicó, en el mejor de los casos, la afirmación de la igualdad en perjuicio de la libertad.

\section{Ciudadanía, ciudadano y una cuestión de género}

La Modernidad y, más específicamente, el triunfo de la burguesía impusieron, dentro del nuevo lenguaje y entre otros, los términos ciudadanía y su derivado ciudadano. Se trata de conceptos claves, vinculados a la afirmación de los derechos individuales, pero también al enmascaramiento de la desigualdad consustancial de las sociedades capitalistas.

Pese a ser un sustantivo femenino, la ciudadanía es un concepto inscripto en la más larga tradición machista, ab initio y de modo sistemático excluyente de las mujeres del campo de las decisiones políticas. En opinión de la socióloga británica Rosemary Crompton, "[1] a ciudadanía es un concepto cargado de género: una categoría que pese a su supuesta 
neutralidad respecto al género incorpora atributos y características esencialmente masculinas tales como la participación en la asistencia social, la participación adulta en la vida económica (el empleo), etc. El concepto de ciudadanía hizo abstracción de las diferencias entre los hombres y las mujeres y, como consecuencia de ello, un sexo (el de los hombres) se convirtió en norma". 7

Las mujeres -al igual que los niños- fueron excluidas de los derechos de ciudadanía con la imputación, ya que no argumento, de "incapacidad", "inmadurez", "constitución natural", "predominio de las emociones" y correlativa "falta de control", "dependencia" (del hombre, sea el padre, el marido e incluso el hermano). Pero a diferencia de los niños, a los cuales la legislación reconocía (y reconoce) la temporalidad acotada de la capitus diminutio, las mujeres, al igual que los dementes, fueron durante largo tiempo condenadas a padecerla de por vida, reducidas a condición de súbditas. Es muy significativo que los grandes teóricos del contractualismo moderno -Thomas Hobbes, John Locke y Jean-Jacques Rousseau- fueran simultáneamente a) creadores de los principios de legitimación de la dominación política fundada en la libertad e igualdad de cada individuo respecto de los demás (que en Hobbes y Locke son derechos naturales y en Rousseau, principios axiomáticos) y b) guionistas de los justificativos de la exclusión explícita de las mujeres del ejercicio y disfrute de tales derechos, para lo cual apelan a la ontología: es la "naturaleza femenina" (de constitución inferior) la que define el carácter subordinado de las mujeres en todas las relaciones sociales que las incluyan. La fractura entre el reclamo de universalidad de los nuevos principios y la adopción de una singularidad masculina es, en cierto sentido, más terrible y patética en Rousseau, en tanto teórico de la democracia radical. Para el ginebrino, la exclusión de las mujeres de la política obedecía, en efecto, a los tres rasgos constitutivos de la "naturaleza femenina": la irracionalidad, el desorden sexual y la heteronomía.

Dos textos son paradigmáticos de la posición roussoniana de radical exclusión política de las mujeres: La nueva Heloísa y "Sofía”, capítulo V de Emilio. Según Rosa Cobo ${ }^{8}$, tanto el pacto social imaginado por Rousseau cuanto su concepto de democracia, eran patriarcales, excluían radicalmente a las mujeres de la ciudadanía y exigían su subordinación como condición de posibilidad de la vida democrática. En tanto excluidas del pacto social, el ámbito privado o doméstico constituía el locus femenino por antonomasia: mientras el varón ejercía su condición de ciudadano con dedicación exclusiva a la vida pública, la mujer aseguraba la reproducción humana. La función reproductora de las mujeres, dentro de la familia, fue defendida también por Hobbes y Locke, sólo que los tres se diferencian por asignarle un objetivo diferente: así, mientras para Hobbes ellas debían parir guerreros que se converti-

7 CROMPTON, Rosemary, Clase y estratificación. Una introducción a los debates actuales, Tecnos, Madrid, 1994, p. 185.

8 COBO, Rosa, Fundamentos del patriarcado moderno. Jean-Jacques Rousseau, Cátedra, Madrid, 1995. 
rían en sujetos obedientes al Estado, para Locke se trataba de emplear el cuerpo femenino para asegurar la transmisión de la propiedad privada a través de hijos consanguíneos con capacidad económica. En el desiderátum de Rousseau, en cambio, la función de las mujeres era tener hijos para formarlos como ciudadanos libres y autónomos. Así, libertad e igualdad no sólo se tornaban retórica: desaparecían por completo. Adicionalmente, cabe señalar que la cuestión de la exclusión de las mujeres del pacto social ha sido muy bien abordada por Carole Pateman. Según su hipótesis, para que pudiese haber contrato social-mediante el cual hombres (varones) libres e iguales establecieron una comunidad en la cual se reconocieron como tales y construyeron un orden social nuevo-debió formularse antes un contrato sexual, a través del cual los varones regularon el acceso sexual al cuerpo de las mujeres, creando una relación de subordinación de éstas a aquellos (a cambio de protección), de magnitud tal que quedaron excluidas de la "firma" del pacto social. El contrato sexual-ocultado por los contractualistas- tornó posible la conversión del derecho "natural" de los varones sobre las mujeres en derecho patriarcal. Pateman sostiene que así como el espacio público es objeto de explicación desde el contrato social, el espacio privado lo es a partir del contrato sexual. ${ }^{9}$

No obstante su difusión y aceptación, ciudadano es una expresión polisémica: a veces es sinónimo de habitante o, incluso, de nacional (es decir, nacido en, o natural de), mientras en otras designa al titular de derechos civiles y/o derechos políticos. Esa polisemia ha confundido, hasta hoy, la cabal interpretación del proceso de construcción de las ciudadanías en América Latina, territorio donde fueron muy significativas la rápida aceptación y difusión de las expresiones ciudadanía y, tal vez más, ciudadano. En efecto, ciudadano, la forma en castellano de la francesa citoyen, fue el trato en las asambleas, en la prensa, en las proclamas... En la Proclama de Coro, por ejemplo, ciudadano era igual a habitante, mientras en el proyecto de Constitución rioplatense elaborado a fines de 1812 por la Comisión Oficial (presidida por Gervasio Posadas), era quien ejercía los derechos cívicos (capítulo VI, artículo 1).

En las décadas finales del siglo XX la cuestión de la ciudadanía se convirtió en un tema notoriamente relevante dentro de las ciencias sociales. Pese a la proliferación de estudios e investigaciones, la diversidad de enfoques y concepciones no ha llevado a una definición consensuada de ciudadanía. Pese a ello, hay coincidencia generalizada en admitir la división trinitaria formulada por Thomas Marshall en las conferencias de 1949, convertidas luego en un texto clásico, Citizenship and Social Class: derechos de ciudadanía civil ("los derechos necesarios para la libertad individual -libertad de la persona, libertad de expresión, de pensamiento y de religión, el derecho de la propiedad, a cerrar contratos válidos y el derecho a la justicia"), política ("derecho a participar en el ejercicio del poder político como miembro de un cuerpo investido de autoridad política, o como elector de los miembros de tal cuerpo") y social ("todo el espectro desde el derecho de un mínimo de bienestar eco-

9 PATEMAN, Carole, The Sexual Contract, Stanford University Press, Stanford, 1988. 
nómico y seguridad al derecho a participar del patrimonio social y a vivir la vida de un ser civilizado conforme a los estándares corrientes en la sociedad"). A cada tipo de ciudadanía corresponde una institución específica, a saber: los tribunales, el parlamento y los consejos del gobierno local, y el sistema educativo y los servicios sociales. En la historia del Reino Unido se constataba una sucesión cronológica que daba cuenta de la consagración de cada una de esas tres ciudadanías en los siglos XVIII, XIX y XX, respectivamente, si bien, argumentaba, los dos últimos se solapaban.

Pese a las objeciones de algunos críticos, que la han achacado proponer un modelo universal de secuenciación de los derechos de ciudadanía, Marshall entendía que la misma se refería a Inglaterra y que estaba dada más por la historia que por la lógica: "Hasta ahora, mi objetivo ha sido el de trazar a grandes rasgos el desarrollo de la ciudadanía en Inglaterra hasta el fin del siglo XIX. Con este propósito, he dividido la ciudadanía en tres elementos: civil, política y social. He tratado de mostrar que los derechos civiles aparecieron en primer lugar, pues fueron establecidos en su forma moderna antes de que se aprobara la primera Reform Act en 1832. A continuación aparecieron los derechos políticos, y su extensión fue una de las principales características del siglo XIX, aunque el principio de la ciudadanía política universal no fue reconocido hasta 1918. Por otra parte, los derechos sociales se redujeron hasta casi desaparecer en el siglo XVIII y principios del XIX. Comenzaron a resurgir con el desarrollo de la educación elemental pública, pero hasta el siglo XX no llegarían a equipararse con los otros dos elementos de la ciudadanía". ${ }^{10}$

La proposición de Marshall generó una tendencia a pensar los procesos históricos de constitución de la ciudadanía en términos evolutivos, siguiendo la secuencia tripartita civil $\rightarrow$ política $\rightarrow$ social, y el orden países desarrollados (más rápidamente) $\rightarrow$ países periféricos (más lentamente), luego fuerte y eficazmente objetada por el británico Michael Mann, para quien los procesos de constitución de la ciudadanía deben estudiarse prestando atención a las diferentes estrategias seguidas por los actores sociales involucrados en los conflictos -en particular, el conflicto de clase-, lo cual significa que tales procesos son distintos y tienen cierta singularidad. ${ }^{11}$

A Marshall, de la ciudadanía le interesaba "especialmente su influencia en la desigualdad social", la cual, como el mismo advertía, remitía a la "formidable cuestión" de las clases sociales. En su opinión, desde fines del siglo XIX "la influencia de la ciudadanía en la desigualdad social ha sido fundamentalmente diferente de la que tuvo en cualquier tiempo pasado. Empero, pese a reconocer la importancia de la clase social, el sociólogo e historiador británico no se ocupó, alegando razones de tiempo (no se olvide que exponía

10 MARSHALL, Thomas Humphrey, "Ciudadanía y clase social", en Reis. Revista Española de Investigaciones Sociológicas, $\mathrm{N}^{\circ} 79$, julio-septiembre, Madrid, 1997, p. 312. La acotación de una secuencia histórica y no lógica, p. 302.

11 MANN, Michael, "Ruling Class Strategies and Citizenship", en Sociology, V. 21, No 37, 1987. 
una conferencia), de "la difícil y tediosa tarea de examinar su naturaleza y analizar sus componentes". ${ }^{12}$ No obstante, quedaba planteado un problema monumental, para cuya solución media biblioteca argumenta en una dirección y la otra media en la contraria: la concesión a, o la conquista de derechos de ciudadanía -sobre todo, pero no sólo, socialespor parte de la clase obrera, ¿fomentaba u ocluía la lucha de clases? Tal vez la respuesta más certera combina ambas proposiciones: es cierto que lograr derechos de ciudadanía - los de la trilogía marshalliana- ha estimulado la lucha por obtener nuevos derechos y, por ende, la conflictividad entre las clases -y esto lo entendieron mejor que nadie los teóricos de la Trilateral Commission y del neoliberalismo-, pero también lo es que la conquista de esos mismos derechos facilitó el pasaje de las políticas revolucionarias a las reformistas y, en el límite, resultó una monumental operación de transformismo orgánico, como bien lo muestran las experiencias del Welfare State europeo y de los Estados de Compromiso Social latinoamericanos, dos mecanismos eficaces para la conservación del capitalismo.

Al igual que Marshall, pero por obvias razones de espacio, no he de ocuparme aquí de la "formidable cuestión", ni siquiera sólo de la ciudadanía, excepto en aquellos trazos gruesos que hacen a lo central de la conflictiva construcción del orden en la América Latina poscolonial.

La ciudadanía - cuyo significado ha variado históricamente desde Aristóteles hasta nuestros días, tanto que, a juicio de algunos autores, el problema debe ser planteado en términos no de un concepto sino de concepciones de la ciudadanía- remite hoy, inter alia, a pertenencia e identidad nacional, participación, comunidad. Se refiere a derechos y está inextricablemente ligada a la cuestión de la igualdad. Dicho de otro modo, la ciudadanía no puede entenderse fuera de su articulación con la inclusión y la exclusión.

"En el mundo moderno [escribe la socióloga española Soledad García] la ciudadanía constituye prácticas legales, económicas, políticas y culturales que definen la participación social y que contrarrestan las desigualdades sociales. En este sentido, la práctica de la ciudadanía proporciona a las personas que difieren en edad, sexo, creencias o color de piel los mismos derechos básicos. Es este aspecto de la ciudadanía el que ha contribuido a legitimar el Estado moderno". Más allá de las varias acepciones y de los distintos modos de entender la ciudadanía, es fundamental la distinción de los significados formal y sustantivo: formalmente, la ciudadanía alude a pertenencia a una determinada comunidad política (un Estado), esto es, tener una determinada "nacionalidad"; sustantivamente, significa posesión de derechos específicos y observancia de ciertas obligaciones dentro de dicha comunidad o Estado. "Las decisiones acerca de quién es ciudadano las toma el Estado, pero la cualidad de la ciudadanía, es decir, los derechos y obligaciones que ésta conlleva, son el resultado de conflictos y de negociaciones entre las fuerzas estructurales políticas y sociales de un país". ${ }^{13}$

12 MARSHALL, Thomas Humphrey, "Ciudadanía y clase social”..., Op. Cit., p. 312.

13 GARCÍA, Soledad, "Ciudadanía en España”, en ALABART, Anna, GARCÍA, Soledad, GINER, 
La asociación ciudadanía-derechos se resume brillantemente en la célebre concisa proposición de Hannah Arendt: la ciudadanía es el derecho a tener derechos. En ese sentido, todo recorte de derechos es una mutilación de la ciudadanía. La cuestión es de suma importancia, pues, en primer lugar, no es igual tener derecho a algo, que tener ese algo: por caso, tener derecho a la vivienda no es lo mismo que tener una casa, de igual modo que tener derecho al trabajo no se traduce necesariamente en tener un empleo. En segundo lugar, como señala el catalán Juan Ramón Capella, a todo derecho corresponde un deber: "afirmar (...) que alguien tiene un derecho implica afirmar que alguien distinto de él tiene un deber. Un deber de hacer o de no hacer, o de respetar lo que haga quien tiene el derecho". La garantía jurídica del cumplimiento de éste corresponde al Estado, encargado de ejercer la coerción sobre quien no cumple con el deber correspondiente a ese derecho. Así, todo ciudadano (particular) afectado en un derecho por el incumplimiento del deber correspondiente de otro ciudadano (también particular) debe ser atendido de manera tal que el primero sea resarcido y el segundo reciba la sanción del caso. Pero para que el principio sea efectivo es necesario que el Estado ejecute su decisión de aplicar la coerción sobre quien ha incumplido su deber.

El problema se complica, añade Capella, cuando inquirimos sobre "¿quién tiene el deber 'correspondiente' a un derecho de libertad?" A diferencia de otros derechos, los de libertad son irrenunciables: un hombre o una mujer puede renunciar, por ejemplo, al derecho de propiedad, mas no puede consentir convertirse en un esclavo. Es cierto que, recuerda Capella, los derechos de libertad son generales y todos los ciudadanos tienen el deber de respetarlos. Pero esa observancia es insuficiente. De allí que se requiera algo más, de una diferencia. "La diferencia consiste [según argumenta el autor catalán] en que a los 'derechos de libertad' les corresponde, además, un deber del Estado. Es sobre todo el Estado quien tiene el deber de respetar tales derechos. ... Los deberes del Estado que garantizan los derechos de libertad (y los 'sociales', etc.) de los ciudadanos son... de naturaleza política", lo cual significa que "la existencia de derechos de libertad no está jurídicamente garantizada porque la constitución que los proclama no está jurídicamente garantizada. Los famosos deberes del Estado están impuestos, pura y simplemente, por una correlación de fuerzas de naturaleza política", esto es, por "los diferentes poderes reales con pretensiones políticas existentes tal como aparecen en la «situación actual» de la pugna entre ellos. ... Los frágiles 'derechos de libertad' de la época moderna se basan, pues, en la convención de respetar los 'derechos de libertad'. Dependen, pues, de $[a]$ quienes convienen". ${ }^{14}$

Ahora bien: la canónica trilogía de Thomas Marshall ha sido cuestionada, desde la perspectiva de la filosofía del derecho, por Luigi Ferrajoli. La crítica del gran jurista italiano se dirige al núcleo duro de la argumentación del británico. Dicho brevemente, argumenta

Salvador (compiladores) Clase, poder y ciudadanía, Siglo XXI Editores, Madrid, 1994, p. 226.

14 CAPELLA, Juan Ramón, Los ciudadanos siervos, Trotta, Madrid, 1993, pp. 140-143; itálicas del autor. 
que: la Déclaration des droits de l'Homme et du Citoyen, del 26 de agosto de 1789, suprimió todas las diferencias de status existentes hasta entonces, salvo dos: el de ciudadano, es decir, la ciudadanía, y el de persona, esto es, de personalidad, extensible a todos los seres humanos. De esa distinción homme / citoyen, incluida en todas las Constituciones, "dependen dos clases de derechos fundamentales: los derechos de la personalidad, que corresponden a todos los seres humanos en cuanto individuos o personas, y los derechos de ciudadanía, que corresponden en exclusiva a los ciudadanos". Así, los que Marshall llama derechos de ciudadanía civil y derechos de ciudadanía social son, para Ferrajoli, derechos fundamentales, mientras que los derechos políticos son los únicos que son derechos de ciudadanía, del ciudadano. El mérito de la Déclaration radicó "en reconocer y sancionar como derechos del hombre los derechos de libertad, y como derechos del ciudadano los derechos políticos, unos y otros esenciales no sólo para el desarrollo del capitalismo, sino también para el de la democracia". ${ }^{15}$

Ferrajoli señala que la tipología de Marshall, al no distinguir dos criterios de clasificación independientes, provoca confusión. Esos criterios de diferenciación aluden a la estructura de los derechos fundamentales, uno, y a los titulares de esos derechos, el otro. El primero de ellos "no tiene nada que ver con la ciudadanía". Propone distinguir cuatro categorías: derechos civiles, derechos políticos, derechos de libertad y derechos sociales, a los cuales agrupa en dos pares: derechos civiles y derechos políticos, que son derechos "cuyo ejercicio consiste en decisiones, es decir, en actos jurídicos que producen efectos por la acción de sus titulares, y que presuponen la capacidad de obrar en el ámbito civil, en el primer caso, y político, en el segundo". La segunda díada -derechos de libertad y derechos socialesson derechos de expectativas (negativas y positivas), los cuales conllevan "por parte de los poderes públicos, prohibiciones de interferencia en un caso, y obligaciones de prestación en el otro". Por lo general, los derechos políticos son de ciudadanía, y los civiles, de la persona, mientras que los derechos de libertad son de las personas y los sociales "pueden ser, y habitualmente son, en parte de la persona y en parte del ciudadano". ${ }^{16}$

No viene al caso ocuparse aquí de esta cuestión con detenimiento, pero me parece pertinente atender a la posición de Ferrajoli. ${ }^{17}$

En América Latina, las expresiones ciudadanía y ciudadano, en su nueva acepción, comenzaron a ser empleadas por algunos hombres en reemplazo de otras más tradicionales. Así, por ejemplo, en 1792, el jesuita (expulso) peruano Juan Pablo Viscardo y Guzmán dirigía su Carta a los españoles americanos a los "Hermanos y compatriotas". En 1806,

15 FERRAJOLI, Luigi, Derechos y garantías. La ley del más débil, Trotta, Madrid, 1999, pp. 99101.

16 Ídem, pp. 104-105.

17 Para una mejor comprensión de la postura de FERRAJOLI véase su libro Derechos y garantías..., Op. Cit., particularmente los capítulos 2 y 4. 
Francisco Miranda abría su Proclama de Coro "a los pueblos habitantes del continente américo-colombiano" con el apelativo "Valerosos compatriotas y amigos", si bien la expresión ciudadano aparece varias veces en el texto. En 1809, otra proclama, la de Manuel Rodríguez de Quiroga, ministro de la Junta de Quito, definía como destinatarios explícitos a los "Pueblos de la América", al tiempo que su presidente, Juan Pío Montúfar, marqués de Selva Alegre, optaba por "Señores" al pronunciar su Arenga en el Cabildo Abierto del 10 de agosto del mismo año. Un mes antes, la Junta Tuitiva de los Intereses del Rey y del Pueblo, constituida en La Plata (Charcas) y presidida por Pedro Domingo Murillo, prefería apelar "A los valerosos habitantes de La Paz".

Previsiblemente, los citoyens aparecieron temprano en el lenguaje de los revolucionarios de la colonia francesa de Saint-Domingue: tal los casos, por ejemplo, de Vincent Ogé - ese campeón de la igualdad, como le llama Pierre Pluchon-, en 1790, y luego de Toussaint Louverture, en los comienzos mismos de la gran insurrección esclava que, como se expuso en el capítulo 3, devino revolución social frustrada, si bien generó las primeras independencia y república de América Latina y la primera república "negra" del mundo. Más tarde, no sólo en la Constitución de 1801 sino también en la proclama de Jean-Jacques Dessalines al pueblo de Haití, anexa al Acta de Independencia ( $1^{\circ}$ de enero de 1804), dirigida a los Citoyens.

También en la América española el apelativo ciudadanos -y/o la variante conciudadanos- apareció tempranamente, según se aprecia, por ejemplo, en el "Discurso preliminar dirigido a los americanos", texto introductorio a la versión en español de la radical Déclaration des Droits de l'Homme et du Citoyen de 1793, que los partícipes de la conspiración de Manuel Gual y José María España realizaron en 1797 en Venezuela. Igualmente se lo encuentra en los "planes de gobierno" preparados por Francisco Miranda en 1801 (sobre la base de un bosquejo presentado al ministro inglés William Pitt años antes). El término fue utilizado, asimismo, por los rioplatenses Mariano Moreno (1810) y Bernardo Monteagudo (uno de los primeros en plantear la cuestión de la ciudadanía, en 1812); por el mexicano Miguel Hidalgo y Castilla en el Manifiesto publicado en Guadalajara en diciembre de 1810; por el neogranadino Antonio Nariño; por el oriental José Artigas en su discurso inaugural del Congreso de Tres Cruces, en abril de 1813; por los chilenos Juan Egaña (proyecto de declaración sobre los Derechos del pueblo de Chile, 1811 y 1813), José Miguel Carrera y Bernardo 0'Higgins (manifiesto conjunto del 4 de setiembre de 1814); por el venezolano Simón Bolívar... En fin, se lo encuentra reiteradamente en artículos, discursos, cartas, Constituciones y proyectos.

En el Río de la Plata, señala Vicente Oieni, el vocablo ciudadano se empleó inicialmente "en relación a la defensa de la patria y el valor en el contexto de las invasiones inglesas". Casi de inmediato, con la Revolución de Mayo y particularmente con el discurso de la 
Gaceta de Buenos Aires, "ciudadano fue experimentando desplazamientos semánticos que lo terminaron emplazando dentro del discurso emancipatorio". ${ }^{18}$

Para los revolucionarios radicales de la década de 1810, al menos en el Río de la Plata, libertad, igualdad y ciudadanía estaban íntimamente entrelazadas. Era la libertad quien convertiría a los hombres en ciudadanos, más aún:

La libertad de los pueblos no consiste en palabras ... Si deseamos que los pueblos sean libres, observemos religiosamente el sagrado dogma de la igualdad

Según escribía Mariano Moreno en la Gaceta de Buenos Aires. ${ }^{19}$

Ahora bien: para los minoría dirigente revolucionaria, cuando se trataba de los pueblos originarios, la libertad, la igualdad y, por ende, la condición de ciudadanos, no se concebía como resultado de un construcción desde abajo, societal, sino el de la decisión de los gobernantes, incluso de un solo hombre, como en el caso de la medida dispuesta, en agosto de 1821, por el general San Martín, a la sazón Protector de la Libertad del Perú, según la cual

En adelante no se denominarán los aborígenes Indios o Naturales: ellos son hijos y ciudadanos del Perú, y con el nombre de Peruanos deben ser conocidos. ${ }^{20}$

En palabras de Vicente Oieni: “Así, con la firma del Libertador del Perú, en un acto de decisión personal, se crea la ciudadanía peruana por decreto. La historia mostró la distancia entre la voluntad revolucionaria y la realidad de los 'indígenas' del Perú cuya integración como ciudadanos aun hoy no se ha concretado por completo. Pero, en aquel momento, para la élite criolla que conducía el proceso revolucionario y la guerra, era central dividir la historia entre un antes y un después, entre lo ilegítimo -la colonización española- y lo legítimo, la independencia y el gobierno del pueblo; para hacerlo, elevó al 'indio' a la categoría de símbolo de una nueva identidad americana". ${ }^{21}$

Aquí se observa una de las primeras y más consistentes decisiones de constitución estatalista de la ciudadanía.

18 OIENI, Vicente, "Imaginar al ciudadano virtuoso. Introducción del concepto de ciudadano en el proceso de emancipación en el Río de la Plata", en ANSALDI, Waldo (coordinador) Calidoscopio latinoamericano. Imágenes históricas para un debate vigente, Ariel, Buenos Aires, 2004, p. 100.

19 Apud OIENI, Ídem, p. 103.

20 En Colección de leyes, decretos y ordenes publicadas en el Perú desde su independencia en el año 1821 hasta el 30 de diciembre de 1830, Imprenta de José Masías, Lima, 1831, p. 21.

21 OIENI, Vicente, “Imaginar al ciudadano virtuoso...", Op. Cit., p. 104. 


\section{Libertad y ciudadanía}

"La introducción del concepto de ciudadano como sinónimo de hombre libre [sostiene Oieni] es una de las innovaciones más significativas del proceso revolucionario rioplatense". Como concepto, "se fue definiendo por oposición y peyoración en relación a términos tales como súbdito, esclavos, siervos. Estas calificaciones se vincularon a la condición de los criollos como sector cuyos méritos y virtudes no eran apreciados por la política modernizante de los Borbones que tendía a fortalecer una burocracia peninsular". En "una situación de postergación y subordinación", añade el autor, el concepto ciudadano se cargó de resonancias emancipadoras tanto en términos colectivos (las colonias) como individuales (la libertad de los particulares). ${ }^{22}$

En noviembre de 1810, Mariano Moreno escribió en la Gaceta de Buenos Aires una expresión que Oieni considera una clara asociación "entre libertad y ciudadanía como principio fundante de una nueva era":

La libertad nos hará ciudadanos. El egoísmo ocupaba a los hombres por entero, porque el siervo no tiene a quien amar sino a si mismo; en delante sabrán esos mismos hombres, que hay una patria. Humildad, obediencia, sufrimiento, esas eran vuestras virtudes como calidades de buenos esclavos: generosidad, valor, amor de la gloria, éstas serán las que honrasen a todo ciudadano. ${ }^{23}$

Así, sostiene Oieni, el "ciudadano virtuoso" fue concebido "como agente imaginario del discurso de ruptura del vínculo colonial". Lo era, también, con sus valores generosidad, valor, amor de la gloria, que lo definían en contraposición con su opuesto, el esclavo, humilde, obediente, sufrido. ${ }^{24}$

El temprano pregonar en favor de los nuevos principios, en particular el de la democracia, no encontró eco en dimensiones estructurales y culturales demasiado fuertes y resistentes ante los cambios. En el fondo, las tres matrices societales sobre las cuales se construyeron las sociedades latinoamericanas generaron coincidencias y diferencias en los planos sociales y culturales que no dejaron de expresarse, con matices, en las formas con las cuales se procesaron los proyectos y los fundamentos del nuevo orden político. Al final del proceso, hacia fines del siglo XIX, la construcción del orden social y político bajo la forma de dominación oligárquica terminó de poner una pesada lápida al proyecto emancipador y postergó largamente el reconocimiento del derecho de las mayorías a decidir por sí mismas el rumbo de la historia.

Para sociedades cuyas clases dominantes invocaron la democracia política como forma

22 Ídem, p.100.

23 Apud OIENI, Ídem, p. 101.

24 Ibídem. 
de dominación, la cuestión de la ciudadanía fue un punto central. Empero, como escribiera Wanderley Guilherme dos Santos -a propósito de Brasil pero extensible a buena parte (si no a toda) América Latina-, el resultado fue la conjugación de un liberalismo doctrinario con un autoritarismo instrumental. El derecho de sufragio -mejor aún: la ciudadanía política, el derecho a elegir y ser elegido- fue objeto de fuertes restricciones por doquier: por razones de clase, de género y de etnia (amén de la de salud mental). Y donde no lo fue, como en el temprano y casi excepcional caso de la provincia de Buenos Aires, que estableció el sufragio universal masculino en 1821, las prácticas políticas y electorales convirtieron, de facto, el derecho en un mero enunciado. Amputaciones similares ocurrieron en el campo de la ciudadanía civil. En una y en otra, entonces, la universalidad de los principios devino en singularidad de los derechos efectivos; mujeres, trabajadores, campesinos, indígenas, afroamericanos, buena parte de los mestizos - en fin, la amplísima mayoría de cada sociedad-siguieron siendo excluidos del acceso a la modernidad.

\section{El breve sueño roussoniano en América Latina}

Como ha mostrado Boleslao Lewin, ${ }^{25}$ las obras de Rousseau llegaron relativamente temprano a América Latina, si bien no tuvieron difusión, pues sus poseedores -básicamente sacerdotes, algunos de ellos funcionarios de la Inquisición- se encargaron de impedirla. Empero, algunos de ellos escribieron para confrontar y descalificar el pensamiento del ginebrino, o lo enseñaron a sus alumnos con igual objetivo. Según el autor, el chileno José Antonio de Rojas -uno de los líderes de la independentista y republicana Conspiración de los Antonios ${ }^{26}$, abortada por las autoridades coloniales en 1780- fue de los iniciales conocedores de las ideas de Rousseau, ya en 1776.

Lewin sostiene que el deán Gregorio Funes fue, en 1790, el primero en hacer mención pública (negativa) de El contrato social en el Río de la Plata. Casi simultáneamente, fray José Antonio de San Alberto, arzobispo de Charcas -que ya había condenado la sublevación de Túpaq Amaru-, despotricaba contra la "seducción de las multitudes" por las ideas de igualdad, independencia y libertad postuladas por Rousseau. A su vez, Mariano Medrano, profesor de Filosofía en el Colegio Carolino de Buenos Aires, atacaba el mismo libro por la defensa de la democracia que hacía su autor. Más o menos por la misma época, en México también lo invocaban para combatirlo fray Cristóbal Mariano Coriche (1783) y fray Servando Teresa de Mier (1791), y la Inquisición procesaba al hacendado José Enderica por leer y comentar El contrato social (1794). Lewin argumenta que principios roussonianos se

25 LEWIN, Boleslao, Rousseau en la independencia de Latinoamérica, Depalma, Buenos Aires, 1980.

26 Así llamada por el nombre de los tres principales conjurados. Además de Rojas, los franceses Antonie Berney y Antonie Gramusset. El plan era de un notable radicalismo revolucionario. 
encuentran en el Discurso Filosófico de fray Melchor de Talamantes (1808) y en documentos derivados del Grito de Dolores, tanto de Miguel Hidalgo y, sobre todo, José María Morelos, quien en "Sentimientos de la Nación", texto leído en el congreso de Chilpancingo, expuso los tres principios básicos del ginebrino: soberanía popular, igualdad de los hombres, libertad ciudadana (en este caso, recortada por el exclusivismo católico). ${ }^{27}$

De algún modo, entonces, la confrontación contra Rousseau en algunos ámbitos educativos no dejó de ser un llamado de atención curiosa sobre su pensamiento. No casualmente, Mariano Moreno y Dámaso Antonio Larrañaga, más tarde un artiguista, fueron alumnos de Medrano. Lewin sostuvo que, en el Río de la Plata, el ideario de Rousseau debió haber trascendido más allá de los claustros educativos, pues fray Baltasar de Quiñones, maestro general de los dominicos, atacó explícita, directa y reiteradamente a El contrato social y a su autor entre 1791 y 1819 .

Un importante centro de conocimiento del pensamiento de Rousseau fue la Universidad de Charcas, donde se formaron Mariano Moreno y Bernardo de Monteagudo, a quienes Lewin calificó, respectivamente, como "el roussoniano argentino (tal vez americano) más decidido" y "el jacobino rioplatense más caracterizado" (aunque más tarde el tucumano abjuró de su posición juvenil).

Por su liderazgo y su acción política concreta, tal vez la mejor realización del pensamiento de Rousseau en el Río de la Plata (y en América toda) fue la del oriental José Artigas, en quien el influjo del ginebrino fue un efectivo "programa político". ${ }^{28}$

En Venezuela, ya en los años 1790 Juan Mariano Picornell, el español inspirador ideológico de la conspiración dirigida por Manuel Gual y José María España (1793), explicitó los principios roussonianos que guiaban a los primeros independentistas, compartidos también por Juan Germán Roscio, Simón Rodríguez y Simón Bolívar.

Presupuestos teóricos de Rousseau fueron incluidos -a veces coexistiendo con otros opuestos- en Constituciones tales como, en Venezuela, la Federal (1811) y las de Mérida (181), Barcelona (1812), Angostura (1819), las neogranadinas de Cundinamarca y Tunja (1811), Mariquita y Antioquia (1812), los proyectos orientales de 1813, la mexicana de Apatzingán, entre otras. Se los encuentra igualmente en la declaración de independencia de Guatemala (1821), en el acta del cabildo de San José de Costa Rica (30 de octubre de 1821), en textos del guatemalteco Pedro Molina y del hondureño José Cecilio del Valle, de los brasileños fray José de Santa Rita Durão, Antonio de Souza Caldas, João Ribeiro (un curo partícipe de la insurrección pernambucana de 1817), Inácio Bento de Loyola, entre otros.

Recientemente, el politólogo mexicano Roberto Breña ha sostenido que el influjo de Rousseau en América Latina fue "menor de lo que se pensó durante mucho tiempo". ${ }^{29}$ Empe-

27 LEWIN, Boleslao, Rousseau en la independencia..., Op. Cit., pp. 143-149.

28 Ídem, p. 102.

29 BREÑA, Roberto, "El primer liberalismo español y su proyección hispanoamericana”, en JAKSIĆ, 
ro, entiendo, la argumentación de Lewin sigue siendo sólida respecto de la importancia y la extensión del pensamiento roussoniano. Pero no puede negarse que se trató de una influencia que, en lo sustantivo de su pensamiento, fue breve. Entre 1815 y 1820 , particularmente con la derrota del proyecto artiguista, el sueño emancipador latinoamericano fundado en las premisas del ginebrino había sido derrotado. Por eso, como escribí en otra ocasión, tuvimos independencia pero no emancipación. Por eso también, con todo lo que es necesario adecuar históricamente a las condiciones del siglo XXI, Jean-Jacques Rousseau sigue siendo actual.

Recibido: 15/04/2012

Aceptado: 19/06/2012

Iván y POSADA CARBÓ, Eduardo (editores) Liberalismo y poder. Latinoamérica en el siglo XIX, Fondo de Cultura Económica, México DF, 2011, p. 75. 